\title{
Numerical Crush Analysis of Thin-Walled Aluminium Columns with Square Cross-Section and a Partial Foam Filling
}

\author{
Mirosław Ferdynus ${ }^{1 *}$, Michał Rogala ${ }^{1}$ \\ 1 Department of Mechanical Engineering, Lublin University of Technology, Lublin, Poland \\ * Corresponding author's e-mail:m.ferdynus@pollub.pl
}

\begin{abstract}
The article presents the results of numerical crush simulations of thin-walled structures with a square cross-section and partial filling with foamed material. The influence of the length of the filling on the values of the energy efficiency index was analysed. Four types of foamed material were subjected to numerical analysis. The research was conducted using FEM in Abaqus 6.14 program. The obtained results were presented in the following forms: load-shortening characteristics, tables and diagrams. The best energy absorbing properties are shown by models filled with aluminium and polyethylene terephthalate foam.
\end{abstract}

Keywords: thin-walled structures, foamed material, crashworthiness indicators, energy absorption

\section{INTRODUCTION}

In the age of rapid technological development in the automotive industry the passive safety of transported people is exceptionally important, especially the proper design of the so-called deformation zone. This zone consists of elements between the bumper and longitudinal, which should be properly designed - part as rigid and part as elastic elements.

Column energy absorbers, also known as crash boxes, mounted directly on the longitudinals [17] are an important element of passive safety systems. The main purpose of installing the crash boxes is to absorb impact energy up to a speed of $15-20 \mathrm{~km} / \mathrm{h}$. Their energy efficiency depends on the type and placement of crush initiators, called triggers. Apart from absorbing part of the energy, crash boxes are of great importance when it comes to time and cost of post-accident repairs in the case of so-called crashes, since they protect longitudinals - elements that are very difficult and costly to repair. Column energy absorbers usually have square, rectangular or circular cross-sections $[9,11]$.
Any type of hole or redrawing dents, if properly located, can play the role of crush initiator. Research on this type of elements began in the 1960s, when first regulations on transport safety were introduced to the automotive industry. Enhancing those numerical methods and simulations contributed to the development of this field. Experimental results could be verified, whereas multi-variant FEM analyses significantly decreased the cost and time of obtaining the results.

Such multi-variant analyses were presented in the study by Chen and Wierzbicki [1], who researched the crush propagation of energy absorption columns in various construction variants. Those columns had no crush initiators (triggers). Profiles reinforced with additional inner walls, so called multi-cell models [8] achieve promising results. Using the aforementioned triggers, forcing the crush initiation to occur in a specific place, allows one to obtain better energy absorbing properties. Works in which crush initiation is performed by various holes [16] where the first plastic fold occurs during impact are also worth mentioning. In the work [3] numerical calculations of aluminium profiles with cylinder dents 
on the side edges were presented. This work investigated the influence of the location and depth of the cylinder dents on the energy absorption properties. In the article [4] a similar issue was presented on the basis of numerical and experimental analyses.

Another group is filled profiles, usually completely. A traditionally used filling material, wellknown for its energy absorbing properties is a honey comb-type thin walled structure. In the work [13] this type of structure was analysed. The first researchers to investigate the filling of a profile with foamed material were Hanssen, Langseth and Hopperstad. At the turn of 19th and 20th centuries they presented publications on the mathematical model and a method of calculating such problems $[5,6]$.

The current article presents the results of the numerical analysis of a hybrid solution in which traditional triggers in the form of spherical indentations on the side surface of the column cooperates with foam filling of a varied length. The main objective of this study is to investigate the influence of the type and length of the foam filling on the behavior of the energy absorber column and its energy absorbing properties.

\section{Crushworthiness idicators}

Typical course of the characteristics loadshortening for thin-walled columns with a square cross-section are presented in Figure 1.

The field under the curve is the measure of energy absorbed by a thin-walled member. This energy can be determined by the formula:

$$
E A\left(d_{x}\right)=\int_{0}^{d_{x}} F(x) d x
$$

where: $d_{x}$ is the crush length and $F(x)$ is the crushing force.

Energy absorbed by the thin-walled member per energy absorber mass unit is called specific energy and designated as SEA (formula 2).

$$
S E A=\frac{E A}{m}
$$

Apart from the course of load in the shortening function, fig. 1 presents the following parameters, very important for the safety and efficiency of the energy absorbing process: PCF- Peak Crushing Force and MCF- Mean Crushing Force. The ratio of those parameters is defined by a very important CLE coefficient (Crash Load Efficiency), expressed by formula 3 :

$$
C L E=\frac{M C F}{P C F} \cdot 100 \%
$$

where: MCF is the mean crush force, described by the dependency:

$$
M C F=\frac{E A\left(d_{x}\right)}{d_{x}}
$$

Another coefficient - Stroke Efficiency (SE) is defined by the formula presented below:

$$
S E=\frac{U}{L_{o}}
$$

where: $\mathrm{L}_{0}$ - initial height, height of a sample before impact [mm] $\mathrm{U}$-maximum shortening of a sample [mm]

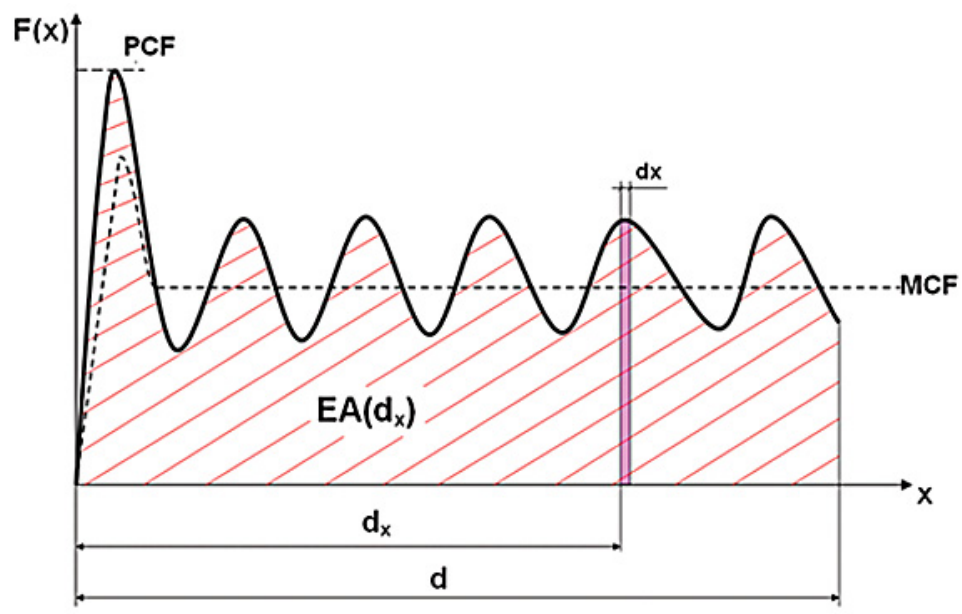

Fig. 1. Exemplary chart load-shortening for thin-walled, axially loaded models [3] 
From the point of view of the efficiency of the energy-absorbing process and the biomechanical assumptions, basing on the minimisation of deceleration it is favourable for the CLE coefficient to be possibly the highest. It can be attained by minimizing PCF and maximizing MCF. It is also suggested that the energy absorption ought to take place on the longest path possible. Further details on the energy efficiency indexes can be found among others in the articles $[4,10,14]$.

\section{Model of the column energy absorber}

Amodel of an aluminium column with a square cross-section and the dimensions $40 \times 40 \mathrm{~mm}$, height $200 \mathrm{~mm}$ and wall thickness $1.2 \mathrm{~mm}$ was subjected to numerical analysis. On the surface of the absorber there are spherical indentations with diameter of $32 \mathrm{~mm}$ and depth $3.6 \mathrm{~mm}$, that is three times the value of the wall thickness, located $30 \mathrm{~mm}$ from the nether edge, as shown in fig. 2. The thin-walled model was filled with four types of foamed material. Foam filling takes the form of a rectangular cube, fitting the inside of the profile. The examined cubes have the following dimensions: cross-section $37.6 \times 37.6 \mathrm{~mm}$, height $40 \mathrm{~mm}, 60 \mathrm{~mm}$ or $80 \mathrm{~mm}$. In total, 12 numerical models, differing in the foam filling's length and foam type were analysed.

The model of the column was designed in Catia V5 software with the use of a surface modelling module Generative Shape Design, then imported to Abaqus 6.14, where the further work on the model, as well as numerical calculations using FEM were conducted. The calculations were performed using two modules. In the standard module, a buckling analysis was performed to obtain the buckling modes and the values of critical forces. The first buckling mode is necessary for the further calculations, since it determines the form of the geometrical imperfection, which disrupts the ideal geometry (shape) of the energy absorber column. This form is introduced to the numerical model through the addition of a procedure to the code. Due to this, in the next stage of calculations - in the Explicit module it is possible to obtain reliable results that are confirmed in experimental testing.

Energy absorbers with a foam filling made of one of the following four materials: aluminium (AL), styrodur (EPS), polyurethane (PU) or polyethylene terephthalate (PET) were subjected to numerical analysis. Material data concerning the foam are presented in Table 2. The material model in the plastic area is defined in Abaqus as a Crushable Foam.

The strain-stress characteristic for foamed materials created based on the data from specialist literature $[2,7,12,15]$ is shown in Fig. 3. Material properties of AW 6063-T6 aluminium alloy, out of which the column was manufactured, are presented in Table 1. This material is characterized by linear hardening.

After importing the model to Abaqus 6.14, it was supplemented with two rigid plates, connected to the edge of the column profile with tietype constraint. Reference points, where virtual sensors were defined, were generated in the rigid plates. In the reference points certain data will be obtained during numerical simulation. In the upper plate the data on displacement, speed and acceleration will be obtained, whereas in the nether plate - reaction force generated. Fig. 4a presents a model of energy absorber with rigid plates and reference points. The plates were imposed with boundary conditions - the bottom plate was disabled, whereas the upper plate was free to move along the $\mathrm{z}$ axis. An impact on the energy absorber with the energy equal $\mathrm{E}_{\mathrm{K}}=1715 \mathrm{~J}$ was applied by subjecting the upper plate to the mass $m=70 \mathrm{~kg}$ and initial speed $V_{z}=7 \mathrm{~m} / \mathrm{s}$. The FEM model was
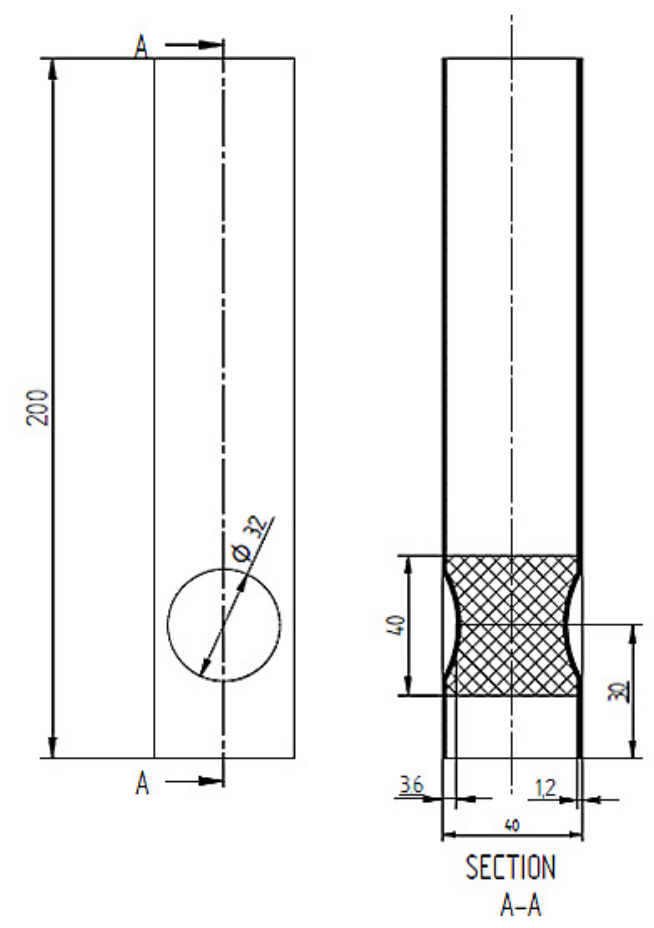

Fig. 2. Technical drawing of the aluminium column with a crush initiator and a foam filling. 
Table 1. Material data of aluminium

\begin{tabular}{|l|c|}
\hline \multicolumn{2}{|c|}{$\begin{array}{c}\text { Aluminium AW6063- T6 } \\
\text { (own experimental research) }\end{array}$} \\
\hline Density $\left[\mathrm{kg} / \mathrm{m}^{3}\right]$ & 2700 \\
\hline Young'sModulus[MPa] & 70000 \\
\hline Poisson's Ratio $[-]$ & 0.33 \\
\hline Proportional limit $\mathrm{R}_{\mathrm{H}}[\mathrm{MPa}]$ & 200 \\
\hline Strength limit $\mathrm{R}_{\mathrm{m}}[\mathrm{MPa}]$ & 280 \\
\hline
\end{tabular}

presented in Fig. 4 b and c. In the column Shell, S4R-type element was used, whereas in the rigid plates Discret Rigid, R3D4-type element.

The models were marked as CF32-3-X-Y, where $X$ describes the type of the foam filling (AL, PET, EPS, PU), whereas $\mathrm{Y}$ - its length in $\mathrm{mm}$. The initial numbers/digits of the designation describe the diameter and depth of the trigger.

Table 2. Material data of the foam types used in numerical testing

\begin{tabular}{|c|c|c|c|c|c|c|}
\hline & Density $\left[\mathrm{kg} / \mathrm{m}^{3}\right]$ & $\begin{array}{c}\text { Young's } \\
\text { Modulus [MPa] }\end{array}$ & $\begin{array}{c}\text { Poisson's } \\
\text { Ratio [-] }\end{array}$ & $\begin{array}{c}\text { Yield strength } \\
\text { (compression) [MPa] }\end{array}$ & $\begin{array}{c}\text { Poisson's } \\
\text { Plastic Ratio [-] }\end{array}$ & $\begin{array}{c}\text { Yield strength (triaxial } \\
\text { compression) [MPa] }\end{array}$ \\
\hline AL & 270 & 60 & 0.33 & 1.702 & 0.015 & - \\
\hline PU & 65 & 5.5 & 0 & 1 & - & 0 \\
\hline PET & 135 & 20.41 & 0.1 & 0.77 & 0.09 & - \\
\hline EPS & 28 & 10 & 0.1 & 0.15 & - & 0.05 \\
\hline
\end{tabular}

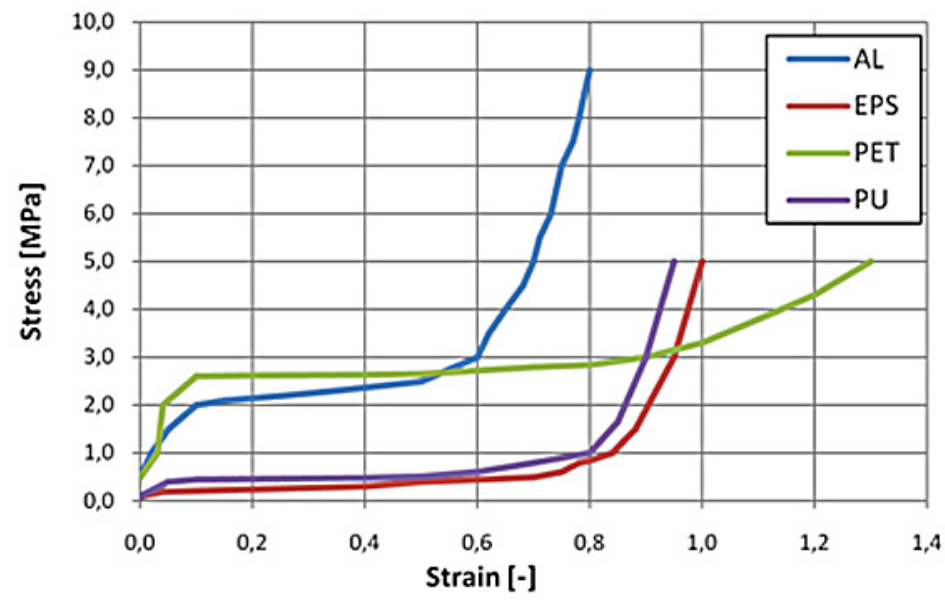

Fig. 3. Stress-strain dependency obtained from the testing of foams used in the energy absorber $[2,7,12,15]$

a)

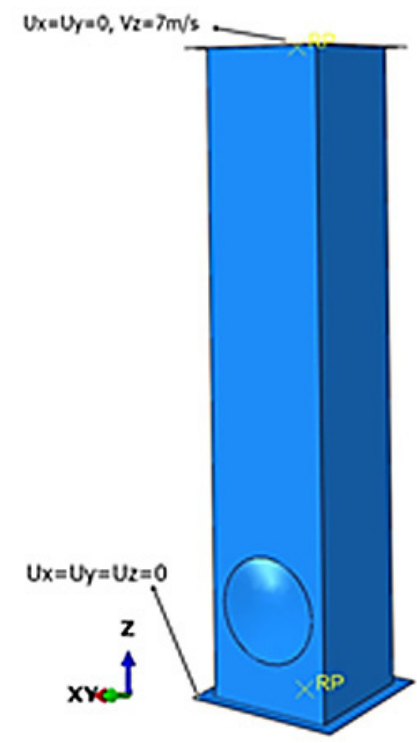

b)

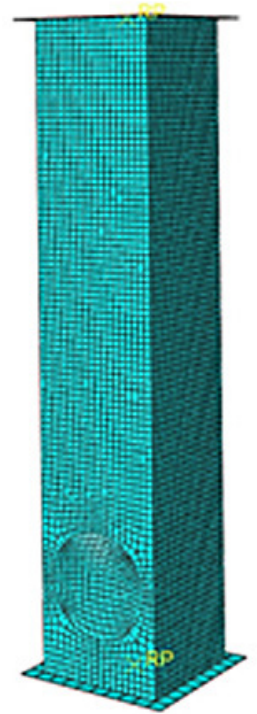

c)

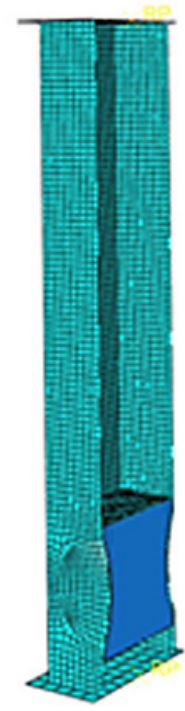

Fig. 4. Energy absorber column model a) assembly of a column with rigid plates with imposed boundary conditions b) FE model c) half of FE model with a visible foam cube 


\section{Results of numerical simulations}

The results of the numerical analysis can be presented using the dependency crushing force shortening. An exemplary diagram created for a model with a $60 \mathrm{~mm}$-long PET filling is shown in Fig. 5. Characteristic points with the structure's deformation state assigned are marked in the diagram. Particular stages of damage of the energy absorber can be observed, along with the occurrence of consecutive peaks.
It can also be observed how the column's height minimally increases elastically upon absorbing the entire energy (stage 9 and 10). Figures $6-10$ present the dependencies crushing force - shortening for all of the examined models, divided on the basis of the type of foam inside the energy absorber. One can notice that the type of foamed material and its length influence the course of the characteristic. Foams with less density (EPS, PU) influence the course of the characteristic to a small extent when the foam cube is $40 \mathrm{~mm}$ or
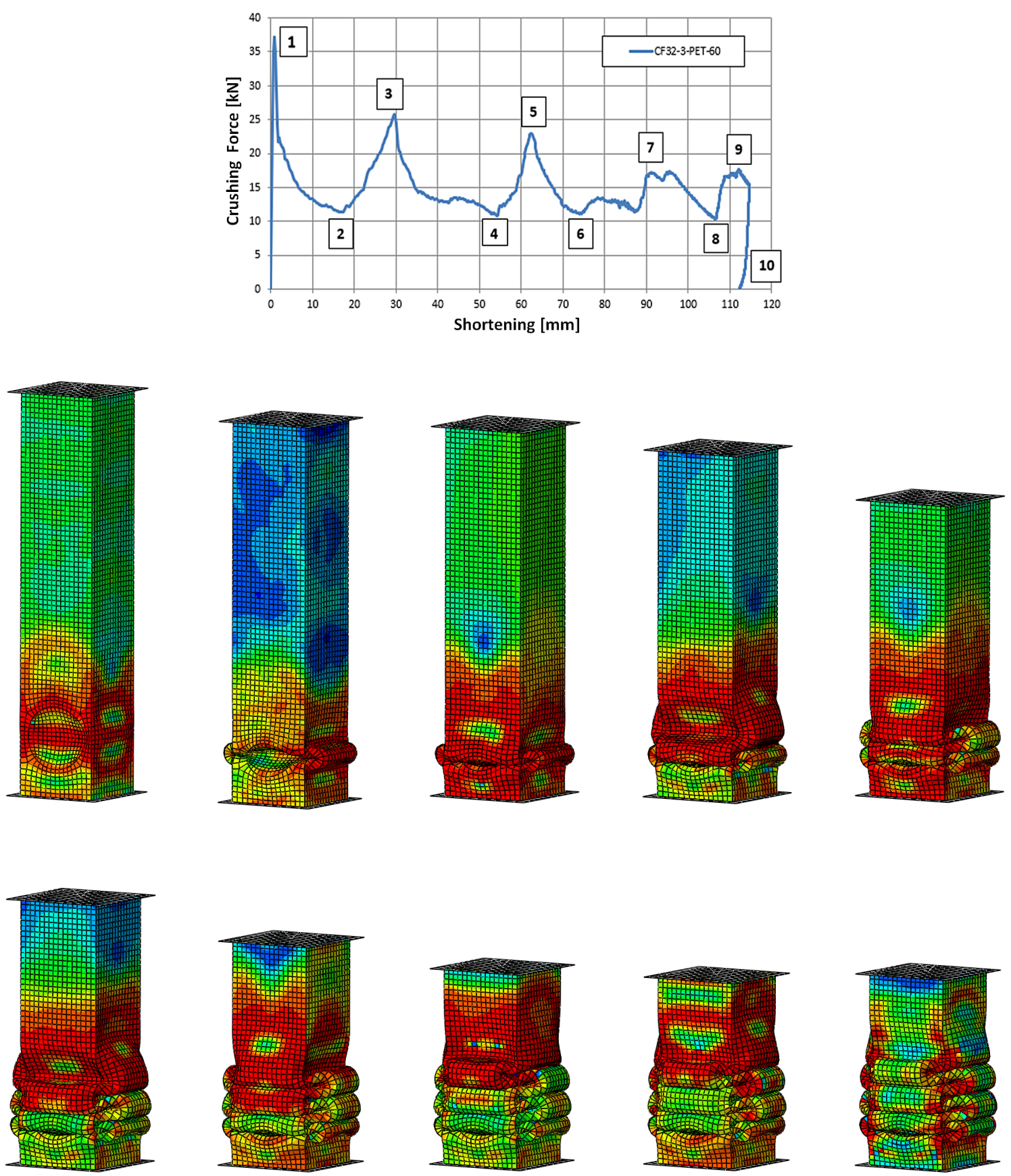

Fig. 5. Load - shortening diagram and stages of crushing process of the specimen CF32-3-PET-60 
Table 3. Crashworthiness indicators and maximum shortening for all models

\begin{tabular}{|c|c|c|c|c|c|}
\hline Model & $\begin{array}{c}\text { U3max } \\
{[\mathrm{mm}]}\end{array}$ & $\begin{array}{c}\text { PCF } \\
{[\mathrm{kN}]}\end{array}$ & $\begin{array}{c}\mathrm{MCF} \\
{[\mathrm{kN}]}\end{array}$ & $\begin{array}{c}\text { CLE } \\
{[\%]}\end{array}$ & $\begin{array}{c}\text { SE } \\
{[-]}\end{array}$ \\
\hline C32-3- E & 133,64 & 38,476 & 12,845 & 33,385 & 0,668 \\
\hline CF32-3- AL 40 & 128,83 & 36,804 & 13,306 & 36,152 & 0,644 \\
\hline CF32-3- AL 60 & 115,53 & 37,105 & 14,751 & 39,755 & 0,578 \\
\hline CF32-3- AL 80 & 90,81 & 37,288 & 18,853 & 50,562 & 0,454 \\
\hline CF32-3-EPS 40 & 133,95 & 36,804 & 12,799 & 34,775 & 0,670 \\
\hline CF32-3-EPS 60 & 120,55 & 37,105 & 14,189 & 38,240 & 0,603 \\
\hline CF32-3-EPS 80 & 119,27 & 37,146 & 14,308 & 38,518 & 0,596 \\
\hline CF32-3-PET 40 & 129,64 & 36,804 & 13,231 & 35,948 & 0,648 \\
\hline CF32-3-PET 60 & 114,67 & 37,105 & 14,886 & 40,118 & 0,573 \\
\hline CF32-3-PET 80 & 96,83 & 37,026 & 17,602 & 47,541 & 0,484 \\
\hline CF32-3- PU 40 & 133,34 & 36,732 & 12,867 & 35,029 & 0,667 \\
\hline CF32-3- PU 60 & 122,59 & 37,190 & 13,019 & 35,005 & 0,613 \\
\hline CF32-3- PU 80 & 120,84 & 37,192 & 12,920 & 34,738 & 0,604 \\
\hline
\end{tabular}

$60 \mathrm{~mm}$ high. A certain influence can be observed in the case of longer cubes. As far as cubes of a higher density are concerned (AL, PET), the influence of the foam filling on the characteristic is noticeable, regardless of the height of the cube.

The results of the calculated values of crashworthiness indicators, along with maximum shortening of the column, measured at the moment when the speed of the impact tup reaches 0 , are presented in table 3. Results obtained for a sample without filling (marked as C32-3-E- empty) are presented for comparison. This data allows a comparison and an assessment of the benefits of foam fillings.

For all models, a slight influence of the filling type and length on the PCF value is noted. (maximum decrease of $3.1 \%$ ). In terms of $\mathrm{MCF}$, the
CF32-3-AL

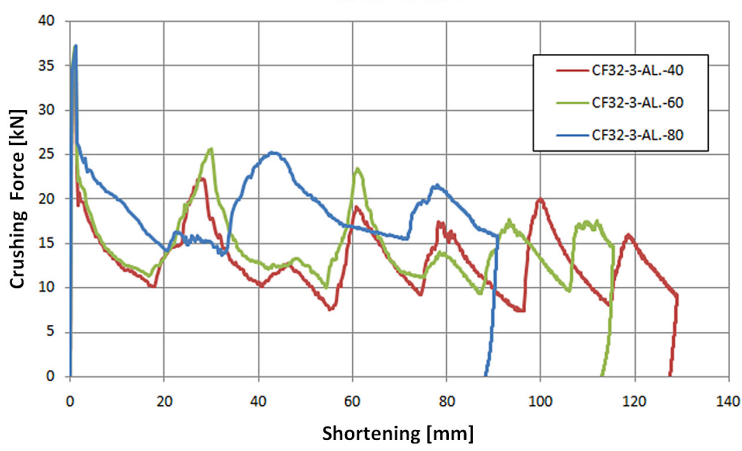

Fig. 6. Load- shortening diagram for the models with aluminium foam filling

CF32-3-EPS

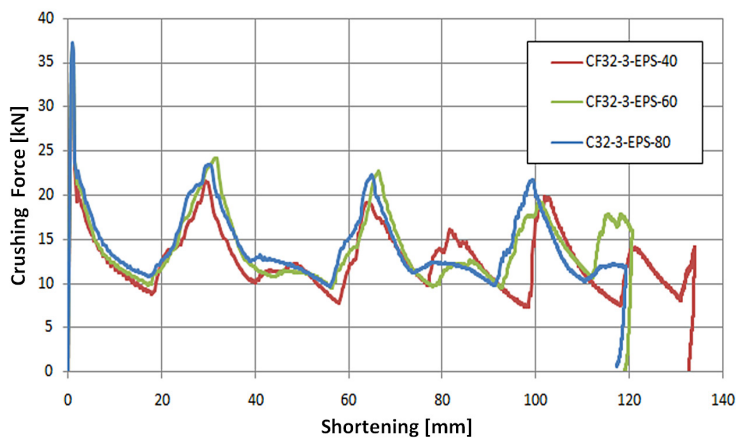

Fig. 8. Load - shortening diagram for models with styrodur foam filling

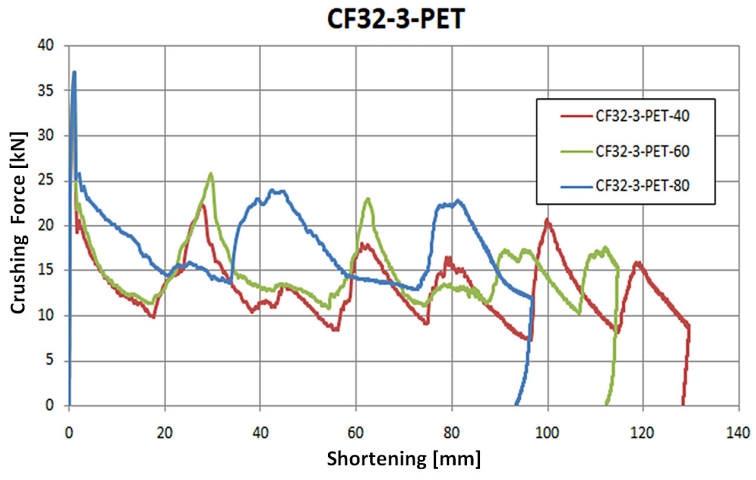

Fig. 7. Load - shortening diagram for models with PET foam filling

\section{CF32-3-PU}

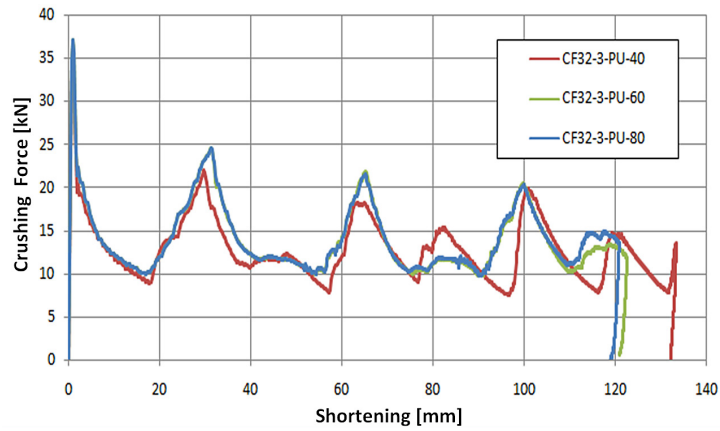

Fig. 9. Load-shortening diagram for models with polyurethane foam filling 
increase ranges from $0.6 \%$ to $46.8 \%$, depending on the type and length of filling. Therefore, it can be stated that the observed increase in the value of CLE is a result of the increase in MCF and not the drop in the value of PCF (see formula 3 ).

The dependency between the values of CLE and SE and the type and length of the foam filling is shown in fig. 10 and 11 . The sample without foam is presented as a sample with the length of the filling equal $0 \mathrm{~mm}$.

The density of the material is the most influential factor in the change of energy absorption indexes. The longer the foam core is, the more visible the aforementioned dependency is.

The values of the SE coefficient (formula 5) depend mostly on the maximum shortening of the sample. Since all of the samples were subjected to impact with similar energy and their initial height was identical, it can be stated that the greater value of shortening, the higher SE coefficient. The samples of high-density foam (AL, PET) and greater length have a low SE coefficient, whereas low-density samples - a high one. High values of the SE coefficient indicate that the filling absorbed little energy. In this case a highly deformed thin-walled structure has a lesser capability of absorbing another portion of energy. Low value of the SE coefficient upon absorbing a portion of energy indicates that fair part of this energy was absorbed by the foam core. In this state of deformation the structure is capable of absorbing another portion of energy. Models CF32-3-AL-80 and CF32-3-PET-80 present the highest value of the CLE coefficient and simultaneously the lowest value of the SE coefficient.

\section{CONCLUSIONS}

The use of a partial foam filling in the area of the crushing initiator was aimed at increasing the energy absorption properties. The results of numerical simulations confirmed such increase, especially for high-density foams and fillings of a greater height. It was also proven that applying partial foam fillings influences the increase of the CLE coefficient, mostly by increasing the MCF force and only minimally by decreasing the PCF force. The latter can be decreased, to a limited extent, by changing the geometrical parameters of the trigger (in that case of a spheroidal

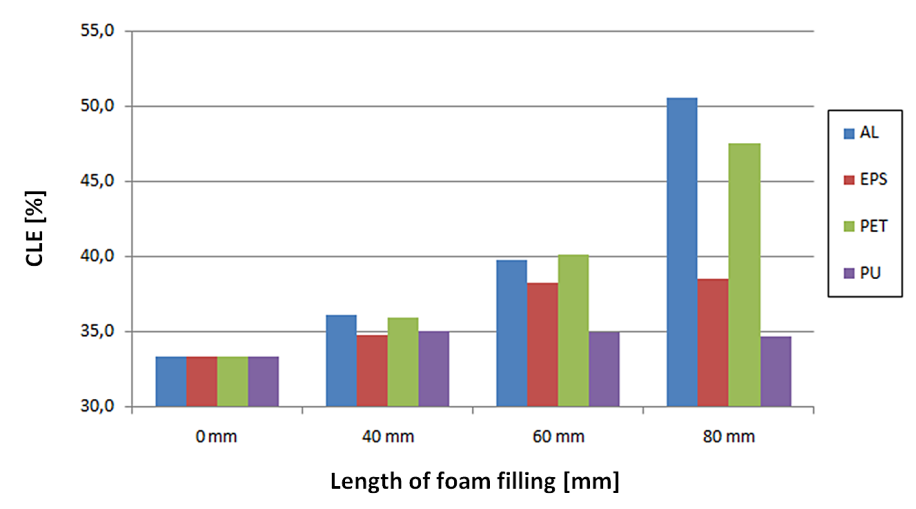

Fig. 10. CLE coefficient for models with varying filling length

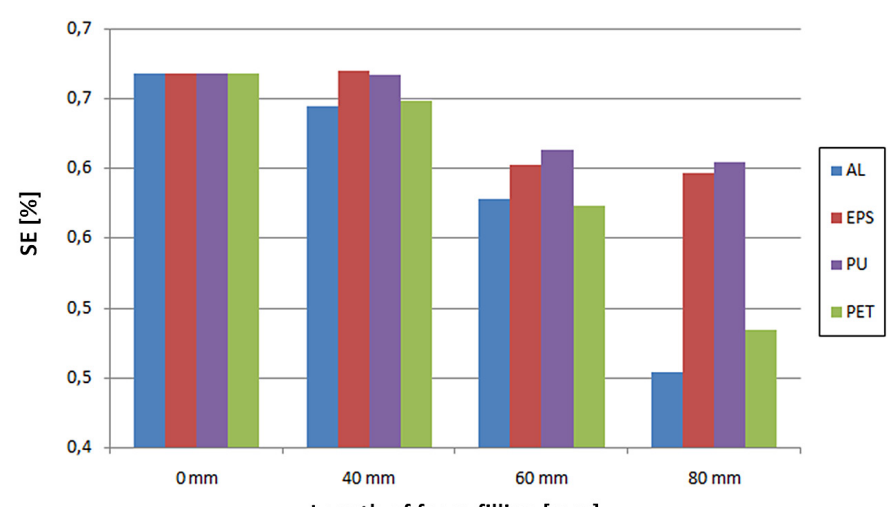

Fig. 11. SE coefficient for models with varying filling length 
indentation). As mentioned earlier, in the comparative analysis of several columns subjected to impact of the same energy, low value of the SE coefficient indicates that the foam filling absorbed a relatively significant portion of energy and the thin-walled member still has the capability of absorbing energy.

The most advantageous model with aluminium foam filling and $80 \mathrm{~mm}$ height showed the increase of the CLE coefficient of over $51 \%$ and the decrease in the SE indicator equal c.a. $32 \%$ in comparison to an empty column.

\section{Acknowledgements}

The project/research was financed in the framework of the project under title "Lublin University of Technology - Regional Excellence Initiative", funded by the Polish Ministry of Science and Higher Education (contract no. 030/RID/2018/19).

\section{REFERENCES}

1. Chen W., Wierzbicki T. Relative merits of singlecell, multi-cell and foam-filled thin walled structures in energy absorption. Thin Walled Structures, 39, 2001, 287-306,https://dx.doi.org/10.1016/ S02638231(01)00006-4

2. Costas M. et al. Static crushing of aluminium tubes filled with PET foam and a GFRP skeleton. Numerical modelling and multiobjective optimization, International Journal of Mechanical Sciences 131-132, 2017, 205-217, https://doi.org/10.1016/j. ijmecsci.2017.07.004.

3. Ferdynus M, Kotełko M. and Kral J. Energy absorption capability numerical analysis of thin-walled prismatic tubes with corner dents under axial impact. Eksploatacja i Niezawodnosc - Maintenance and Reliability, 20(2), 2018, 252-259. http:// dx.doi.org/10.17531/ein.2018.2.10.

4. Ferdynus M., Kotełko M. and Urbaniak M. Crashworthiness performance of thin-walled prismatic tubes with corner dents under axial impact - Numerical and experimental study.144, 2019. https:// doi.org/10.1016/j.tws.2019.106239

5. Hanssen A.G., Langseth M, Hopperstad O.S. Static and dynamic crushing of circular aluminium extrusions with aluminium foam filler. International Journal of Impact Engineering, 24, 2000, 475-507, https://doi.org/10.1016/S0734-743X(99)00170-0.

6. Hanssen A.G., Langseth M, Hopperstad O.S. Static crushing of square aluminium extrusions with aluminium foam filler. International Journal of Me- chanical Sciences, 41, 1999, 967-993, https://doi. org/10.1016/S0020-7403(98)00064-2.

7. Mozafari H. et al, Finite element analysis of foamfilled honeycomb structures under impact loading and crashworthiness design, International Journal of Crashworthiness, 21:2, 2016,148-160, DOI: 10.1080/13588265.2016.1140710.

8. Nikkhah H. at al, The effect of different shapes of holes on the crushing characteristics of aluminum square windowed tubes under dynamic axial loading, Thin-Walled Structures, 119, 2017, 412-420. http://dx.doi.org/10.1016/j.tws.2017.06.036

9. Hsu S.S. and Jones N. Quasi-static and dynamic axial crushing of thinwalled circular stainless steel, mild steel and aluminium alloy tubes, International journal of crashworthiness, 9:2, 2004, 195-217, DOI: 10.1533/ijcr.2004.0282.

10. Kotełko M., Ferdynus M., Jankowski J., Energy absorbing effectiveness- different approaches, Acta Mechanica et Automatica, 12(1), 2018, 54-59, DOI: 10.2478/ama-2018-0009.

11. Liu Y.-C. and Day M.L., Simplified modelling of thin-walled box section beam, International Journal of Crashworthiness, 11:3, 2006, 263-272, DOI:10.1533/ijcr.2005.0409

12. Masso-Moreu Y. and Mills N.J., Impact compression of polystyrene foam pyramids, International Journal of Impact Engineering, 28(6), 2003,653676. DOI:10.1016/S0734-743X(02)00148-3

13. Mohammadiha O., H. Beheshti and Haji Aboutalebi F. Multi-objective optimisation of functionally graded honey comb filled crash boxes under oblique impact loading, International Journal of Crashworthiness, 20:1, 2015, 44-59, DOI: 10.1080/13588265.2014.970398.

14. Reddy T.J., Rao Y.V.D. and Narayanamurthy V., Thin-walled structural configurations for enhanced crashworthiness, International Journal of Crashworthiness, 23:1, 2018, 57-73, DOI: 10.1080/13588265.2017.1306824

15. Xu T. et al, Finite element analysis of indentation of aluminium foam and sandwich panels with aluminium foam core, Materials Science \& Engineering A, 599, 2014, 125-133. DOI: 10.1016/j. msea.2014.01.080

16. Zhang Y.et al, (2018) Crashworthiness study for multi-cell composite filling structures, International Journal of Crashworthiness, 23:1, 32-46, DOI: 10.1080/13588265.2017.1304169

17. Zhou P. et al. Dynamic bending behaviour of magnesium alloy rectangular thin-wall beams filled with polyurethane foam, International Journal of Crashworthiness, 21:6, 2016, 597-613, DOI:10.1 080/13588265.2016.1208715 